\title{
Raccoon (Procyon lotor) Diets Shed Light on Baylisascaris procyonis Roundworm Prevalence
}

\author{
Rigley $\mathrm{S}^{1 *}$, Ingle $\mathrm{M}^{1}$, Gathany $\mathrm{M}^{2}$, Knox $\mathrm{C}^{3}$ and Dunbar $\mathrm{SG}^{3}$ \\ ${ }^{1}$ The Master's University, 21726 Placerita Canyon Rd, Santa Clarita, CA, USA \\ ${ }^{2}$ Cedarville University, 215 N Main Street, Cedarvile, OH, USA \\ ${ }^{3}$ Loma Linda University, 11234 Anderson St, Loma Linda, CA, USA
}

*Corresponding author: Stephanie Rigley, The Master's College, 21726 Placerita Canyon Rd, Santa Clarita, CA 91321, USA, Tel: 7024133759; E-mail: srigley@masters.edu

\section{Research Article \\ Volume 1 Issue 2}

Received Date: September 07, 2017

Published Date: September 22, 2017

DOI: $10.23880 /$ jenr-16000110

\section{Abstract}

The raccoon, Procyon lotor, is the definitive host for raccoon roundworm (Baylisascaris procyonis), which causes a dangerous neurological disease known as larva migrans encephalopathy in intermediate hosts. As omnivores, raccoons rely on a variety of food items. Parasitized animals may exhibit altered eating habits and diets, and may undergo genetic variations as a result of parasite abundance. In this study, we analyzed the diets of necropsied raccoons from nine townships of Clark and Greene Counties, Ohio, by examining their stomach contents. We measured the mass of plant material found in raccoon stomachs and recorded the prevalence of B. procyonis. Mean mass of plant material varied among the nine townships surveyed $(0.88 \mathrm{~g}-6.40 \mathrm{~g})$, indicating a correlation between raccoon diet and regional landscape. The townships with the least amount of agriculture had the greatest difference between all raccoons and $B$. procyonis infected raccoons $\left(r^{2}=0.40\right)$. These results suggest that the complexity of raccoon diet exceeds that which can be explained by agricultural landscape alone. These findings help us better understand the relationship between $B$. procyonis and raccoon diet, therefore helping us to understand the ecological impacts of parasites on animal behavior.

Keywords: Procyon lotor; Raccoon; Baylisascaris procyonis; Parasites

\section{Introduction}

Parasites affect their hosts as well as their ecological environments. Changes in biogeographic patterns play an influential role in parasite abundance, while providing much needed insight into aspects of disease ecology [1]. The environmental impact of parasites is often overlooked due to their negligible biomass. Lafferty (2006) [2] focused on the statistical significance that parasite inclusion has on trophic levels of accepted food web representations. He found the inclusion of parasites in food webs increased both nestedness and connectedness, in addition to altering food web chain length, links, and species richness. Food webs which integrate parasitic involvement no longer represent lowtrophic levels as the most vulnerable, but instead place mid-trophic levels in the most vulnerable position. By proposing that top predators may not be at the highest 


\section{Journal of Ecology \& Natural Resources}

trophic level, Lafferty (2006) [2] displayed how food web topology is greatly altered by parasitism, resulting in drastic changes in population dynamics.

A successful parasite-host relationship depends on multiple biogeographical and mechanistic factors that contribute to infection intensity. Possible contributing factors include host availability, geographic location, and parasite lifecycles. Transmission of such parasitic organisms varies, yet most often occur via ingestion of infected intermediate hosts. Such transmission is demonstrated by the white-footed mouse, Peromyscus leucopus, which becomes infected with the nematode, Pterygodermitites peromysci, when consuming camel cricket cysts [3]. Nematomorphs cause hosts to find and submerge themselves in freshwater which aligns with the parasites lifecycle requirement of transitioning from a terrestrial host environment to an aquatic environment [4].

Another study demonstrated the ability of Pomphorhynchus laevis, an acanthocephalan parasite, to alter the drifting behavior from one region of a river to another in its intermediate invertebrate host, the amphipod crustacean, Gammarus pulex. The introduction of P. laevis to Gammarus roeseli, a sympatric host, did not result in the same pattern of drifting behavior as seen in G. pulex [5].

While parasites impact their ecological environments, the environment also plays a role in host nutrition, which is linked to parasite intensity. Nutrition is one of the main contributing factors that impact the ability of a host to regulate parasite establishment, growth, and resistance.

This directionality of benefit is defined as a non-mutual symbiotic relationship, as only the parasite receives benefit from the relationship. Ezenwa demonstrated nutritional specificity by observing a reduction in host resilience and infection resistance during periods of reduced protein intake [6]. Host diet is a prime indicator of parasite prevalence, revealing patterns unique to particular species. In many fish and bird species, greater helminth diversity is observed in omnivores, whereas in some primate species, folivores have increased nematode diversity.

These variations reveal host diet to be an independent variable contributing to diversity and abundance of parasitic organisms [7]. Host diet can also play a role as a dependent variable, particularly when viewed from a genetic perspective. Parasites are capable of altering the expression of host genes which can result in a modification of phenotypic-altering behaviors and may affect aspects of protein synthesis and other biochemical process. Both parasites and environmental factors are capable of evoking phenotypic changes that can alter host behaviors through processes, such as methylation and acetylation [4]. The role of host diet as either an independent or dependent variable illustrates its importance in the dynamic relationship between parasite and host.

The raccoon, Procyon lotor, adapts to a wide variety of resources, therefore displaying high diversity in both diet and foraging behaviors. Raccoons are highly adaptive meso-carnivores, and are successful in many ecosystems due to their consumption of a wide variety of flora and fauna $[8,9]$. Barton and Roth suggested that raccoon diet choice might be influenced by multiple factors in addition to food item abundance, including dispersal patterns, raccoon density, and population age structure [10]. These factors facilitate increased population distribution, particularly across North and Central America, often resulting in alterations of feeding behaviors when confronted by new environments leading to locationspecific diets and foraging patterns [8]. Rulison, et al. found that suburban raccoons primarily feed on plant material, whereas those that reside in areas near bodies of water appear to primarily prefer crustaceans; the most abundant prey item in that habitat or ecosystem [9]. Additionally, raccoons thrive in areas of human development where there is an absence of large predators. Raccoons that reside in areas subject to predator removal rely less on plant material compared to raccoons that inhabit urbanized environments due to more diverse prey availability, and also display increased survival and reproductive rates $[10,11]$.

The purpose of this study was to investigate the impact of $B$. procyonis intestinal prevalence and mean intensity of infection on the diet of $P$. lotor. We hypothesize that parasite prevalence and mean intensity of infection will explain diet better than landscape features alone.

\section{Materials and Methods}

We conducted this study on raccoons from Greene and Clark Counties in Southwest Ohio. These counties are made up of mostly agricultural lands, and include many dense population centers. Native landscape without development makes up the smallest portion of all but three of the townships surveyed. We collected raccoons from Beavercreek, Miami townships, and Xenia in Greene County, as well as from German, Greene, Harmony, Mad 
River, Moorefield, and Springfield townships, and the City of Springfield in Clark County (Table 1). These townships functioned as the sampling scale for this study. We obtained landscape data from Ingle et al. [12].

Raccoons used in this study were collected by six fur trappers who captured the raccoons on private property with the permission of landowners. Captures were conducted from November 10 through December 9, 2012. A total of 232 raccoon entrails were collected and the entrails from the trapped raccoons were obtained either on the day of trapping or after storage in a $-20^{\circ} \mathrm{C}$ freezer until we were able to retrieve the carcasses (within 72 hours). From the raccoons collected, the viscera were dissected out and placed into two freezer bags labeled with the date of collection, the trapper responsible for the raccoon, and the township or city where the raccoon was trapped. All samples were stored at $-20^{\circ} \mathrm{C}$ until necropsied. We necropsied the full length of the small intestines, collecting any B. procyonis found. The parasites were preserved in $70 \%$ ethanol for verification and future analyses. Raccoons were then classified as either $B$. procyonis positive or negative. We conducted diet analyses on the stomachs of 190 raccoons to determine the amount of plant content consumed by each raccoon. The remaining 42 raccoons were disposed of due to the extent of decay or extensive damage during the removal of the entrails.

We compared the proportion of landscape modified as agriculture among the sample sites selected. Using $\chi^{2}$ analysis for equality of distributions, we assessed the proportions of landscapes modified by agriculture, testing the null hypotheses that all sample sites have the same proportions of landscapes modified (Table 1 ).

\begin{tabular}{|c|c|c|c|c|c|}
\hline Township & $\begin{array}{c}\text { Average Plant Mass of } \\
\text { All Necropsied } \\
\text { Raccoons (g) }\end{array}$ & $\begin{array}{c}\text { Average Plant Mass of } \boldsymbol{B} . \\
\text { procyonis Infected } \\
\text { Raccoons }\end{array}$ & $\begin{array}{c}\text { Percent } \\
\text { Change } \\
\text { of Plant } \\
\text { Mass }\end{array}$ & $\begin{array}{c}\text { Total Area } \\
\text { in } \\
\text { Hectares } \\
\text { (Ha) }\end{array}$ & $\begin{array}{c}\text { Proportion of } \\
\text { Landscape } \\
\text { Modified by } \\
\text { Agriculture }\end{array}$ \\
\hline Beavercreek & 0.879 & 1.169 & 0.3289 & 5752 & 0.5144 \\
\hline German & 8.888 & 17.339 & 0.9610 & 8641 & 0.7298 \\
\hline Greene & 2.667 & 2.64 & 0.0097 & 9243 & 0.8039 \\
\hline Harmony & 6.146 & 4.875 & 0.2068 & 12921 & 0.8603 \\
\hline Mad River & 4.122 & 5.873 & 0.4246 & 8415 & 0.6626 \\
\hline Miami & 3.839 & 2.827 & 0.2637 & 6683 & 0.7106 \\
\hline Moorefield & 1.892 & 1.019 & 0.4615 & 8657 & 0.5711 \\
\hline Springfield & 2.001 & 3.62 & 0.8084 & 8835 & 0.5503 \\
\hline Xenia & 6.403 & 6.384 & 0.0029 & 11391 & 0.7157 \\
\hline
\end{tabular}

Table 1: Analysis of B. procyonis parasite prevalence and intensity in necropsied raccoons was conducted to investigate the relationship between parasitic infection and raccoon diet. The data summary table represents average plant mass found in the stomach contents of necropsied raccoons, percent changes of the observed plant masses, and landscape features specific to raccoons found in each township examined in Southwest Ohio. Data were separated to distinguish between total necropsied raccoons and infected necropsied raccoons.

We assessed the mean plant content of total raccoons necropsied and B. procyonis infected raccoons necropsied. Using a one-way ANOVA test, we determined the mean, variance, and $p$-value of both infected and uninfected raccoons of each township. Using the data from the ANOVA tests and $\chi^{2}$ analysis, we calculated the percent change of the plant masses found in all raccoon stomachs necropsied to the plant masses found only in B. procyonis infected raccoons as per region captured. For the percent change of consumed plant mass, we compared infected raccoons to the total raccoons according to township (Figure 1). We omitted the data from the townships of Springfield City and German as a result of too few counts. 


\section{Journal of Ecology \& Natural Resources}

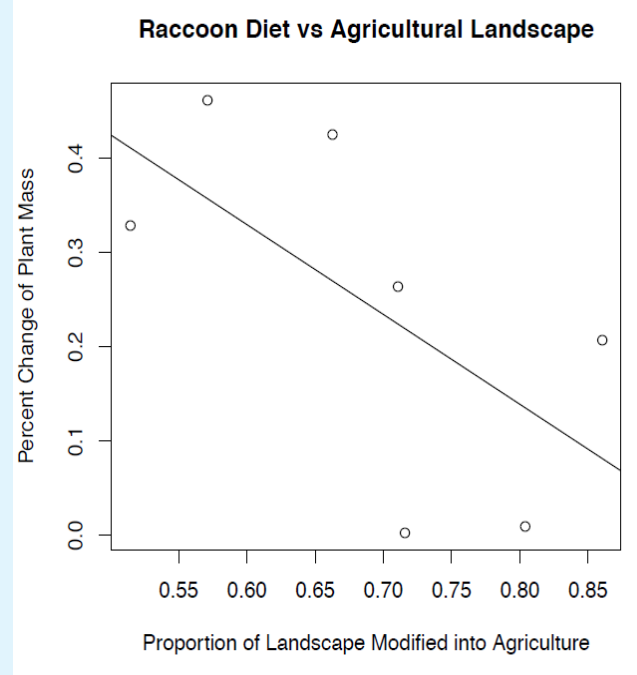

Figure 1: Analysis of B. procyonis parasite prevalence and intensity in necropsied raccoons was conducted to investigate the relationship between parasitic infection and raccoon diet. Following the ANOVA and $\chi 2$ analysis of parasite prevalence and intensity in necropsied raccoons from townships in Southwest Ohio, we constructed a simple linear regression which depicts the relationship between the percent change of infected to uninfected raccoons and the percent agriculture of the township. Graphical analysis demonstrated a negative relationship between percent changes of plant material found in the stomach contents to the percent agriculture of the townships surveyed.

\section{Results}

The proportion of landscape modified as agriculture varied significantly among townships $\left(\chi^{2}=46488.40, p<\right.$ 0.001) leading us to reject our null hypothesis. In Beavercreek Township, which has an agricultural coverage of $51.0 \%$, the average plant mass of all raccoons was $0.88 \mathrm{~g}$, yet $1.17 \mathrm{~g}$ for B. procyonis infected raccoons, resulting in a percent change of $32.9 \%$.

Considering the average plant mass of all raccoons to infected raccoons, a percent change range of $0.20 \%$ in Xenia Township to $46.2 \%$ in Springfield City was observed. Percent change of plant mass correlated significantly with percent agriculture $\left(r^{2}=0.40\right)$. There is a negative relationship between percent change of plant material in stomach to percent agriculture demonstrating that as percent agriculture land coverage increases, the percent change between the plant mass of all necropsied raccoons, and that of necropsied raccoons infected with $B$. procyonis, decreases (Figure 1).

The mean and variance of plant material found in the stomachs of all necropsied raccoons was determined according to township via a one-way ANOVA. The average mass ranged from 0.88 with a variance of $6.69 \mathrm{~g}$ plant material in Beavercreek Township to 6.40 with a variance of $159.17 \mathrm{~g}$ in Xenia Township. ANOVA analyses demonstrated that the amount of plant material found in the stomach contents of all necropsied raccoons varies significantly (All: $\mathrm{F}=1.21, p=0.30$; Infected: $\mathrm{F}=0.72, p=$ 0.67 ) among the nine townships examined, indicating that the resident location of raccoons is directly related to their diet (Table 2).

We used a second one-way ANOVA to determine the mean and variance of plant material found in the stomachs of only those raccoons infected with $B$. procyonis. Results ranged from 1.02 with a variance of $1.65 \mathrm{~g}$ in Moorefield Township, to 6.39 with a variance of $206.92 \mathrm{~g}$ in German Township. Results of the second ANOVA indicated that the previous relationship of diet and township factored out when analyzing only $B$. procyonis infected raccoons. The mean and variance of the percentage of plant material found in the stomach contents of all raccoons, as well as for B. procyonis infected raccoons were determined with respect to townships via ANOVA calculations (All: $\mathrm{F}=2.03, p=0.05$; Infected: $\mathrm{F}=1.67, p=0.12$ ) (Table 2). Results for percent of plant content for all raccoons varied from $1.30 \pm 8.03 \%$ in Beavercreek Township, to 6.02 with a variance of $45.29 \%$ in Mad River Township. Infected raccoon results ranged from 1.23 with a variance of $2.48 \%$ in Moorefield Township to 9.42 with a variance of $264.62 \%$ in German Township.

\begin{tabular}{|c|c|c|}
\hline & $\begin{array}{c}\text { All Raccoons } \\
\text { Necropsied from } \\
\text { Surveyed } \\
\text { Townships }\end{array}$ & $\begin{array}{c}\text { B. procyonis Infected } \\
\text { Raccoons Necropsied } \\
\text { from Surveyed } \\
\text { Townships }\end{array}$ \\
\hline \multicolumn{3}{|c|}{ Mean of Average Plant } \\
\hline $\begin{array}{c}\text { Mass of All } \\
\text { Townships (g) }\end{array}$ & 4.093 & 5.083 \\
\hline ANOVA F & 2.026 & 1.67 \\
\hline ANOVA P-Value & 0.046 & 0.116 \\
\hline ANOVA F Crit & 1.99 & 2.04 \\
\hline
\end{tabular}

Table 2: ANOVA analysis was conducted to represent the dynamics of raccoon parasitic prevalence and intensity according to agricultural townships of Southwest Ohio. We constructed a table to represent the details of our one- 


\section{Journal of Ecology \& Natural Resources}

way ANOVA results of both the total necropsied raccoons and the B. procyonis infected necropsied raccoons. These data were presented in addition to the overall mean of plant mass found in the stomach contents of both groups of necropsied raccoons found within the combined surveyed townships of Southwest Ohio.

\section{Discussion}

Raccoon stomach contents varied among the nine townships. Location can alter methods of foraging to acquire food, therefore creating differences in overall diet based on urban or agricultural regions [13]. Although variances in agricultural percentages supports substantial deviation in raccoon stomach contents among the nine townships, such variances fail to account for the stomach content deviations within individual townships. When altered demographic patterns are explored, we can better understand the biogeographic factors affecting parasite abundance and, therefore, the effect parasites have on foraging behavior [1].

Infected raccoons among townships had more similar stomach contents than infected raccoons did compared to uninfected raccoons of the same township. According to ANOVA calculations, initial calculated relationships between townships and stomach plant mass contents disappeared with the inclusion of parasite infection. Parasitic prevalence explains variations of stomach contents within individual townships and demonstrates that additional factors, besides agricultural regions, contribute to deviations in foraging patterns. Percentage of agricultural areas of townships no longer serves as an indicator. The stomach contents of B. procyonis infected raccoons displayed how raccoon diet functions as a successful indicator of parasite presence above regional type. Parasite richness is, therefore, highly dependent on host diet. This correlation has been observed in the parasitic relationship of primates and Platyhelminthes, in which host invertebrate diet had a substantial impact on complex life-cycle parasite exposure [7].

The diet of raccoons, specifically the grams of plant material consumed, can better be explained by $B$. procyonis prevalence. ANOVA calculations of consumed plant mass support parasitic infection as a suitable predictor of diet, despite similar calculations involving percentage of plant material revealing a less significant correlation. This demonstrates that other variables in addition to agricultural regions must be accounted for when assessing $P$. lotor diet. The increased energy demands from the parasite could cause raccoons to select foods that are energy rich in addition to readily accessible. It is also possible that the prevalence of $B$. procyonis in raccoons phenotypically alters the behavior of its host. Other researchers have observed phenotypic changes caused by other parasites, such as $D$. dendriticum, which alters the behavior of ants, its intermediate host. When an ant becomes infected, it ascends to the top of a blade of grass, awaiting its consumption by a cow or sheep, the definitive hosts of $D$. dendriticum. Additional phenotypic changes observed include changes in host coloring, size, and shape, which can be caused by genetic suppressions resulting from DNA methylation and histone acetylation [4]. Genetic suppressions induced by $B$. procyonis could account for changes observed in the foraging patterns and diets of raccoons.

Our study supports the idea that alterations in diet occur in response to $B$. procyonis prevalence, therefore making parasite prevalence a useful indicator of raccoon diet. Although raccoon necropsies are highly involved and pose potential harm due to zoonosis, they are the most practical way to analyze variables affecting parasite prevalence. The current study analyzed raccoons trapped during the late winter, limiting our understanding of region, diet, and parasite prevalence of raccoons due to unknown deviations which may occur throughout the other seasons. Trapping and performing necropsies on raccoons during all seasons of the year would allow us to further develop a model for predicting both prevalence and intensity of $B$. procyonis by including migratory changes, as well as resource utilization due to seasonal availability. This expansion of data would enhance our understanding of the important role symbionts play in helping to shape diet choice, and potentially behavioral patterns, of raccoons.

\section{Acknowledgements}

We are grateful for the help Dr. Kristen Page provided in guiding us through the prevalence portion of the project. Mindy Vasser, Kara Yutzy, Ashlie Nolan, Jaynee Bartsch, Carrie Rowlands, and undergraduate student's laboratory assistants provided valuable assistance with necropsies and data collection. Dr. William Hayes in the Department of Earth and Biological Sciences (LLU) provided insightful guidance and suggestions on an earlier version of the manuscript. We are also thankful to Dave Pitstick, Dave Linkhart, and Steve Hiller for providing raccoon gut samples. Financial support for this project came from the Department of Science and Mathematics at Cedarville University. The department had no part in any aspect of this project other than 
providing the funding for the research. We would also like to thank Christopher Marquez for his contribution to previous versions of the manuscript. Lastly, we would like to thank the members of the Marine Research Group (LLU) and two anonymous reviewers for their input on the editing of the manuscript.

This is Contribution Number 29 of the Marine Research Group (LLU).

\section{References}

1. Blakeslee AMH, Altman I, Miller AW, Byers JE, Hamer $\mathrm{CE}$, et al. (2012) Parasites and Invasions: A Biogeographic Examination of Parasites and Hosts in Native and Introduced Ranges. Journal of Biogeography 39(3): 609-622.

2. Lafferty KD, Dobson AP, Kuris AM (2006) Parasites Dominate Food Web Links. Proc Natl Acad Sci USA 103(30): 11211-1216.

3. Luong LT, Grear DA, Hudson PJ (2014) Manipulation of host-resource dynamics impacts transmission of trophic parasites. Int J Parasitology 44(10): 737- 742.

4. Poulin R (2010) Parasite Manipulation of Host Behavior. Advances in the Study of Behavior 41: 151186.

5. Lagrue C, Kaldonski N, Perrot-Minnot MJ, Motreuil S, Bollache L (2007) Modification of Hosts' Behavior By A Parasite: Field Evidence For Adaptive Manipulation. Ecology 88(11): 2839-847.

6. Ezenwa VO (2004) Interactions among Host Diet, Nutritional Status and Gastrointestinal Parasite Infection in Wild Bovids. International J Parasitology 34(4): 535-542.
7. Vitone ND, Altizer S, Nunn CL (2004) Body size, diet, and sociality influence the species richness of parasitic worms in anthropoid primates. Evolutionary Ecology Research 6: 183-199.

8. Parsons AW, Simons TR, Allan F O'Connell Jr, Stoskopf MK (2011) Demographics, diet, movements, and survival of an isolated, unmanaged raccoon Procyon lotor (Procyonidae, Carnivora) population on the Outer Banks of North Carolina. Mammalia 77(1): 2130 .

9. Rulison El, Luiselli L, Burke RI (2012) Relative Impacts of Habitat and Geography on Raccoon Diets. The American Midland Naturalist 168(2): 231-246.

10. Barton BT, Roth JD (2007) Raccoon removal on sea turtle nesting beaches. J Wildlife Management 71(4): 1234-1237.

11. Prange S, Gehrt SD, Wiggers EP (2004) Influences of Anthropogenic Resources on Raccoon (Procyon Lotor) Movements and Spatial Distribution. J Mammalogy 85(3): 483-490.

12. Ingle $M E$, Dunbar $S G$, Gathany $M A$, Vasser $M M$, Bartsch JL, et al. (2014) Predicting Baylisascaris Procyonis Roundworm Prevalence, Presence and Abundance in Raccoons (Procyon Lotor) of Southwestern Ohio Using Landscape Features. Int J Parasitol Parasites Wildl 3(2): 113-117.

13. Page LK, Gehrt SD, Robinson NP (2008) Land-Use Effects on Prevalence of Raccoon Roundworm (Baylisascaris Procyonis). J Wildl Dis 44(3): 594-599.

14. Houte SV, Ros VI, Van Oers MM (2013) Walking with Insects: Molecular Mechanisms behind Parasitic Manipulation of Host Behaviour. Mol Ecol 22(13): 3458-3475. 